\title{
A DIVERSIFICAÇÃO E INOVAÇÃO DO INVESTIMENTO EM PME's NO ÂMBITO DO PROGRAMA LEADER I EM PORTUGAL ${ }^{+}$
}

\author{
Francisco Diniz ${ }^{*}$ \\ Fernanda Nogueira ${ }^{* *}$
}

\begin{abstract}
Pensar em desenvolvimento rural é, também, pensar na emergência, consolidação e diversificação do tecido empresarial, qualquer que seja a fileira de produção onde se enquadrem as PME's (Pequenas e Médias Empresas). Foi neste sentido que seleccionámos para análise de estudo as PME's criadas e apoiadas no âmbito do programa comunitário LEADER I (Ligações Entre Aç̧̃es de Desenvolvimento da Economia Rural), visto tratar-se de um programa destinado à revitalização de economias rurais. Neste sentido, e com todas as limitações que, por certo, se nos deparam, gostaríamos de ver respondidas algumas, se não todas, das seguintes questões: Quem foram os promotores destas PME's? Quais as regiões $e$ sectores de actividade mais abrangidos por estes investimentos? Será que as PME's criadas e apoiadas contribuíram significativamente para a diversificação do tecido empresarial das respectivas economias locais? Em termos sociais, qual a sua contribuição para o emprego? Serão estas PME's inovadoras ao ponto de contribuirem para a melhoria da qualidade de vida das populações locais?
\end{abstract}

\footnotetext{
* Professor Auxiliar do Departamento de Economia e Sociologia da Universidade de Trás-os-Montes e Alto Douro.

** Assistente do Departamento de Economia e Sociologia da Universidade de Trás-os-Montes e Alto Douro.
} 


\section{INTRODUÇÃO}

Pensar em desenvolvimento rural é também pensar na emergência, na consolidação e na diversificação do tecido empresarial, qualquer que seja a fileira, onde se enquadram as PME's (Pequenas e Médias Empresas). Mas desenvolvimento implica investimento aos mais diversos níveis. No entanto, sendo o investimento, na economia e na empresa, um acto de criação de bens de produção durante uma unidade de tempo, podemos considerá-lo como uma das principais explicações do desenvolvimento, aceitando, para tal, que o desenvolvimento ultrapassa o investimento, no sentido em que proporciona crescimento, sendo, por isso, um meio para a sua efectivação.

No entanto, para suscitar vontades, individuais e colectivas, a empreender em actividades económico-financeiras em meio rural, não basta apenas financiar. É necessário que todos os agentes, locais e centrais, responsáveis, directa ou indirectamente, por todo o quadro conceptual que hoje vivemos, estabeleçam medidas que visem: a criação de um ambiente favorável à emergência de iniciativas e à identificação de quem tem capacidade de empreendimento, tanto individual como colectivo com vista a impulsionar, acompanhar, dar vida aos projectos capazes de dinamizar os sectores de actividade existentes, criar empregos e desenvolver novas actividades; organizar, em colaboração com outros organismos, dispositivos coerentes que permitam, no momento certo, colocar à disposição dos empresários, existentes e potenciais, os serviços mais adequados. Foi neste sentido que seleccionámos, para análise de estudo, as PME's criadas e apoiadas no âmbito do programa comunitário LEADER I (Ligações Entre Acções de Desenvolvimento da Economia Rural), visto tratar-se de um programa destinado à revitalização da economia rural.

Assim, entre todas as categorias de investimento que se poderiam propor, mencionaremos apenas, neste estudo, por um lado, a dissociação do investimento pelos sectores secundário (produção) e terciário (serviços) e, por outro, o que distingue o investimento público do investimento privado. Mas, porque pretendemos direccionar a nossa análise no sentido do binómio investimento/desenvolvimento, será de todo conveniente verificar não só o montante de capital investido, nas PME's, mas, em simultâneo, o factor trabalho, isto é, qual a contribuição desse mesmo capital para a criação de novos postos de trabalho, sendo que estes últimos podem de alguma forma contribuir para a melhoria da qualidade de vida das populações locais e fixação da própria população ao meio, sobretudo das camadas jovens.

Sabemos que, um dos muitos obstáculos com que as PME's se debatem, em confronto com as GE (Grandes Empresas), é a dificuldade de financiamento adequado ao investimento. Dada a estreita correspondência 
existente entre financiamento e desenvolvimento e tendo presente que os principais meios de financiamento à criação das PME's LEADER foram os capitais privados e públicos e as ajudas comunitárias, é certamente lícito perguntarmos de que forma foram "subsidiados" estes investimentos, uma vez que já em 1952 Herber Frankel (citado por Figueiredo em 1982) chamava a atenção para o facto da dimensão "social do desenvolvimento" não se esgotar nem consistir principalmente numa visão voluntarista da acção política, ficando mesmo espantado que se considere que o investimento de capital produza automaticamente rendimento ou que se espere que o produto industrial cresça de forma cumulativa. Para Frankel, "o problema não consiste em apagar a lousa dos países subdesenvolvidos e escrever nela as nossas equações técnicas e económicas, mas antes em reconhecer que diferentes povos têm diferentes linguagens de acção social e detêm, e de facto exerceram-nas durante muito tempo, aptidões peculiares para resolver os problemas do seu próprio tempo e lugar; aptidões que devem ser ainda mais desenvolvidas na sequência do seu próprio passado para satisfazer as exigências do futuro" (citando Frankel, Figueiredo, 1982: 152). O que significa que a conversão de capital externo em capital produtivo pode não representar um efectivo processo de desenvolvimento, mas tão-só uma forma de consumo de capital, à qual o autor chama "investimento empobrecedor" (Figueiredo, 1982: 154).

Ainda citando Frankel, Figueiredo refere que apostar única $\mathrm{e}$ exclusivamente no investimento, pondo de lado uma renovação do interesse pelas diferenças entre as estruturas sociais dos países desenvolvidos e subdesenvolvidos, é o mesmo que "gastar dinheiro para curar a doença, sem saber muito bem em que é que esta consiste" (Figueiredo, 1982: 155).

São estas diferenças que deixam, segundo o mesmo autor, de ser encaradas como reflexos do atraso económico para se converterem nas suas causas. "Pela sua própria natureza, o crescimento económico é impossível se as instituições económicas e sociais permanecerem inalteradas. E, à medida que o desenvolvimento económico se acelera, só se torna auto-sustentado se as instituições económicas e sociais forem criadas ou adaptadas às necessidades da economia em mutação" (citando Willian H. Nicholls, Figueiredo, 1982: 156). Entramos, assim, no quadro institucional do desenvolvimento, dentro do qual tentaremos analisar, apenas, o contributo da função empresarial, na sua dimensão PME's, sejam estas de capital público ou privado.

Neste sentido, e com todas as limitações que por certo se nos vão deparar, gostaríamos de ver respondidas algumas, se não todas, das seguintes questões ao longo deste trabalho: Quem foram os promotores destes projectos? Quais as regiões e sectores de actividade mais abrangidos por tais investimentos? 
Será que as PME's criadas e apoiadas contribuíram significativamente para a diversificação do conjunto industrial das várias economias locais? Estarão estas mesmas empresas a contribuir para $o$ incremento da capacidade exportadora das regiões onde se inserem ou, pelo contrário, não serão capazes de ultrapassar as suas escalas localmente orientadas, representando assim um travão ao estabelecimento de outras empresas locais com o mesmo objectivo? E em termos sociais, qual é a sua contribuição para o emprego? Serão estas PME's inovadoras ao ponto de contribuirem para a melhoria da qualidade de vida das populações locais?

\subsection{O Programa LEADER}

Em 1988, quando da publicação do documento "O Futuro Do Mundo Rural", a Comissão das Comunidades Europeias (CCE) manifestava a preocupação de se evitarem rupturas económicas e sociais, graves, no seio da Comunidade, alertando assim para a necessidade de se conservar "um modelo europeu de desenvolvimento rural" baseado na promoção da pequena empresa familiar e num ordenamento equilibrado do território. $O$ mesmo documento afirmava ainda que a comunidade dispunha já de numerosos instrumentos de ordem financeira e política que permitiram uma intervenção no processo de desenvolvimento rural, mas "é forçoso reconhecer que eram por vezes mal adaptados, mal coordenados e nem sempre coerentes. (...) A comunidade tem intervido de forma dispersa no mundo rural, por toda uma série de medidas que podiam ter impacto no desenvolvimento mas que, na maior parte dos casos, não prosseguiram de modo sistemático e específico esse objectivo" (CCE, 1988: 90).

Neste sentido e pretendendo ser uma estratégia inovadora de desenvolvimento rural, de carácter experimental e demonstrativo, o programa de iniciativa Comunitária, LEADER I, foi lançado pela CE (Comunidade Europeia) em 1990, definindo como objectivo geral melhorar as possibilidades de desenvolvimento das áreas rurais, apoiando directamente as iniciativas colectivas $e$ individuais de desenvolvimento empreendidas pelas comunidades locais, ou seja, fomentando a mobilização da base para o topo do potencial local. O carácter inovador reside na programação e gestão feitas ao nível do território abrangido por parceiros institucionais, económicos e sociais reunidos no seio de um GAL (Grupo de Acção Local) e, simultaneamente, na rede que agrupa todos os grupos em torno de uma Célula de Animação LEADER (Jornal Oficial das Comunidades Europeias, 1991). 
Eșta iniciativa foi destinada a zonas rurais elegíveis ao abrigo dos objectivos 1 e $5 b^{1}$ do Artigo $n^{\circ} 1$ do Regulamento 2052/88 do Conselho da reforma dos Fundos Estruturais Comunitários, que correspondem a 55\% de todo o território da Comunidade. Dado que Portugal se encontra totalmente inserido nas regiões objectivo 1 , todo o território nacional pode beneficiar do programa, tendo para tal sido constituídos $20 \mathrm{GAL}$ (s), os quais cobriram $36 \%$ do território nacional e $15 \%$ da população total (Jornal Oficial das Comunidades Europeias, 1991).

O tipo de financiamento utilizado foi a subvenção global, sendo as diferentes iniciativas asseguradas por verbas provenientes dos Estados Membros e dos três Fundos Estruturais (FEOGA, FEDER e FSE), com um orçamento comunitário de 442 milhões de ecus para os 3 anos de duração do Programa (1991/1994) e um total de 217 GAL's em toda a CE (Comunidade Europeia) (Leader Magazine, 1992).

A aplicação das verbas previstas no programa foi feita em zonas previamente definidas e caracterizadas, independentemente de qualquer divisão administrativa já existente, designadas por ZI (Zona de Intervenção). Estas deveriam: ser homogéneas no que respeita às potencialidades de desenvolvimento; ter uma população entre 5000 e 100000 habitantes (o que corresponde na maioria dos casos a territórios inferiores à categoria administrativa NUTE III); e não incluir zonas urbanas. Qualquer entidade pública ou privada, na sua qualidade de pessoa colectiva, com intervenção directa no desenvolvimento de áreas rurais poderia ser beneficiária (Jornal Oficial das Comunidades Europeias, 1991).

Assim, pretendendo-se colocar em vigor soluções inovadoras de carácter exemplar para o conjunto das 217 zonas rurais, assegurando a melhor integração possível entre acções sectoriais, convencionou chamar-se Programa ao conjunto dos 217 territórios associados às iniciativas de acompanhamento da rede e Projecto ao conjunto das operações conduzidas por um GAL (Campagne, 1994: 7). Estas operações/acções deveriam ser estruturadas em sete eixos (Medidas) de actuação (Jornal Oficial das Comunidades Europeias, 1991):

Medida 1 - Apoio Técnico ao Desenvolvimento Rural;

Medida 2 - Formação Profissional e Ajudas à Contratação;

Medida 3 - Turismo em Espaço Rural;

Medida 4 - PME's Artesanato e Serviços de Apoio;

Medida 5 - Valorização e Comercialização dos Produtos Locais;

Medida 6 - Outras Medidas;

Medida 7 - Funcionamento do Grupo de Acção Local. 
Mas, ao candidatarem-se ao LEADER, os grupos estavam a assumir a responsabilidade de adoptarem como sua a filosofia subjacente a esta iniciativa comunitária. Tal facto é passível de ser detectado a partir da leitura da Comunicação aos Estados Membros, publicada no Jornal Oficial das Comunidades Europeias em 1991, a qual, apesar de se apresentar como "modelo global" condiciona, de certa forma, o processo de aplicação ao nível local. Uma das grandes limitações são as suas fronteiras de aplicação (rural, no sentido de não urbano, projectos pequenos, nível local e áreas de intervenção limitadas aos domínios deixados em aberto por Programas Operacionais Regionais), não se incentivando interdependências do tipo: rural/urbano, local/regional, pequeno/grande, endógeno/exógeno, que favoreçam a superação de tais fronteiras.

\subsection{A Crescente Importância das PME's para o Desenvolvimento Local}

Os impactos de um processo de (re)estruturação do tecido produtivo local são completamente distintos, se as entidades envolvidas são uma GE e se dispõem de posições dominantes ou apenas secundárias, tanto em termos geográficos como na actividade ou no emprego local. Mas esta análise nem sempre foi relevante, já que pouca foi a importância dada, no período fordista do pós-guerra, às PME's por parte de economistas e decisores políticos, então muito mais preocupados com as economias de escala. Esta posição assentava na ideia generalizada de que as PME's, devido à sua organização rudimentar, fraca capacidade de gestão e tecnologias atrasadas, iriam desempenhar um papel cada vez mais residual nas economias industriais avançadas, à medida que o processo de desenvolvimento económico fosse intensificando os processos de integração e concentração (Pinder, 1994).

Porém, esta situação alterou-se a partir de finais da década de 70 . O impacto da recessão sobre as perspectivas de emprego, no domínio das grandes empresas, e as novas teorias sobre o facto de serem as PME's que criam a grande maioria dos novos postos de trabalho acabaram por apoiar a conclusão segundo a qual uma nova dinâmica de crescimento das PME's poderia vir a constituir uma solução para o problema do desemprego. Por outro lado, e para muitos autores, a flexibilidade da PME não deixa de oferecer vantagens, face à produção em massa da GE, normalmente com estruturas produtivas mais rígidas. A produção em massa requer investimentos elevados. S6 é lucrativa em mercados suficientemente grandes para absorver, com regularidade, a sua enorme capacidade, de modo a manter 
todos os seus recursos de produção continuamente utilizados. Este tipo de produção colide também com a artesanal, onde a flexibilidade deu ao artesão maior habilidade e capacidade de criar produtos variados (diversificação), desenvolvendo a sua pequena empresa, tentando ultrapassar desta forma, passo a passo e com alguma consistência, a mais recente recessão mundial (Piore e Sabel, 1984). Assim, a norma passou a ser o encorajamento e o apoio financeiro ao sector das PME's.

No domínio académico, as PME's e as novas atitudes empresariais passaram a ser associadas a características como a competitividade, a capacidade inovadora e a flexibilidade, o que lhes conferia uma evidente vantagem sobre as grandes organizações. Exemplos a referir, neste sentido, são as experiências japonesa, alemã e italiana.

Este facto é facilmente confirmado quando analisamos a empresa europeia tipo, que não é mais do que aquilo a que se chama, no vocabulário comunitário, uma micro-empresa ${ }^{2}$. As micro-empresas representam, na Europa Comunitária, a quase totalidade das empresas locais. Em toda a Europa, existem 14 milhões de micro-empresas. Na Comunidade Europeia, do total das empresas, cerca de $92 \%$ são pequenas empresas, $6 \%$ médias empresas e apenas $2 \%$ grandes empresas (Leader Magazine, $\mathrm{n}^{\circ} 5,1994: 6$ ).

Em 1988, enquanto as grandes empresas representavam 26 milhões de postos de trabalho, as PME's eram responsáveis por 62 milhões (16 milhões de trabalhadores independentes e 46 milhões de trabalhadores por conta de outrem), ou seja, $70 \%$ do emprego total nos sectores secundário e terceário (sem contar com os empregados na administração pública) da CE (Leader Magazine, $\mathrm{n}^{\circ}$ 5, 1994:6).

Quanto à estrutura empresarial portuguesa, as PME's assumem igualmente uma particular representatividade. Esta representatividade é evidente, quer se considerem indicadores como o número de empresas e o emprego, quer o valor acrescentado, a produção ou as exportações. Com efeito as PME's representavam, ao nível nacional, em 1993, cerca de:

- $99.8 \%$ do número de empresas portuguesas;

- $79.8 \%$ do volume de emprego;

- $68.1 \%$ das remunerações;

- $63.5 \%$ da formação bruta do capital fixo;

- $65.5 \%$ do valor bruto da produção;

- $65.7 \%$ do valor acrescentado bruto;

- mais de 50\% das exportações (IAPMEI, 1993).

Estes números são, sem dúvida, elucidativos do peso das PME's na estrutura empresarial portuguesa. Parece, no entanto, interessante verificar uma outra realidade. É que, com efeito, dentro do grupo formado pelas 
PME's os escalões dimensionais mais baixos assumem uma particular relevância. Neste sentido podemos afirmar que, em 1993, mais de 55\% das empresas portuguesas tinham dimensão inferior a 5 trabalhadores. Se a este escalão somarmos as empresas que empregam entre 5 a 9 trabalhadores, conclui-se que cerca de $78 \%$ das empresas nacionais não atingem 10 efectivos, ou seja, encontram-se dentro do conceito habitual de micro-empresa.

\section{Quadro 1 \\ EMPRESAS POR ESCALÃO DIMENSIONAL EM 1993, EM PERCENTAGEM}

\begin{tabular}{|c|c|c|c|c|c|c|c|c|c|c|}
\hline \multicolumn{10}{|c|}{ Escalão Dimensional número de trabalhadores-\% de empresas } \\
\hline $0-4$ & $5-9$ & $10-19$ & $20-49$ & $50-99$ & $100-199$ & $200-399$ & $400-499$ & $500-999$ & $>-1000$ & Total \\
\hline 55,6 & 22,3 & 11,4 & 6,9 & 2,2 & 1,0 & 0,4 & 0,07 & 0,1 & 0,07 & 100 \\
\hline
\end{tabular}

Fonte: Departamento de Estatística do MESS - Quadros de Pessoal 1993, in IEFP, 1995.

Em relação aos sectores de actividade, observa-se uma distribuição homogénea, em que se destacam os sectores do comércio por grosso e retalhista $(14,7 \%$ do total), indústria têxtil $(11,7 \%)$ e indústria alimentar bebidas e tabaco $(9,2 \%)$. Aplicando o critério já definido para PME, verifica-se que os sectores dominados pelas GE são: indústria alimentar, bebidas e tabaco, indústria têxtil, indústria de produtos químicos e fibras sintéticas, Indústria metalúrgica de base, fabricação de equipamentos eléctricos, fabricação de material de transporte, construção, transporte e armazenagem e actividades financeiras. Nestes sectores as grandes empresas representam respectivamente, $5,2 \%, 8,1 \%, 9,1 \%, 15 \%, 6,7 \%, 16,7 \%, 21,1 \%, 21,4 \%$, $22,2 \%$ e $38,5 \%$ do número total de empresas. Os sectores dominados pelas PME's nacionais são: agricultura e pescas, indústrias extractivas; indústrias de madeira e cortiça, fabricação de artigos de borracha, fabricação de produtos minerais, fabricação de máquinas e equipamento, indústria transformadora não extractiva, comércio por grosso e retalhista, alojamento, restauração e serviços a empresas. Nestes as PME's constituem 100\% do total de empresas, excepto para os sectores de fabricação de produtos minerais e fabricação de máquinas e equipamentos que representam $97,9 \%$ e $95,7 \%$, respectivamente. 


\section{Quadro 2 \\ DISTRIBUIÇÃO POR ACTIVIDADE ECONÓMICA (CAE) EM 1993, EM PERCENTAGEM}

\begin{tabular}{|l|c|c|c|c|c|}
\hline $\begin{array}{c}\text { Classificação Segundo } \\
\text { a CAE }\end{array}$ & $\begin{array}{c}\text { Micro- } \\
\text {-Empresas }\end{array}$ & $\begin{array}{c}\text { Pequenas } \\
\text { Empresas }\end{array}$ & $\begin{array}{c}\text { Médias } \\
\text { Empresas }\end{array}$ & $\begin{array}{c}\text { Grandes } \\
\text { Empresas }\end{array}$ & Total \\
\hline Agricultura e Pescas & 33,3 & 33,3 & 33,3 & 0,0 & 100 \\
Ind. Extractivas & 22,2 & 66,7 & 11,1 & 0,0 & 100 \\
Ind. Alim./Bebi/Tabaco & 13,8 & 36,2 & 44,8 & 5,2 & 100 \\
Ind. Textil & 2,7 & 20,3 & 68,9 & 8,1 & 100 \\
Ind Produtos de Couro & 0,0 & 36,4 & 54,5 & 9,1 & 100 \\
Ind. Madeira e Cortiça & 26,1 & 43,5 & 30,4 & 0,0 & 100 \\
Ind. Pasta de Papel & 15,0 & 30,0 & 50,0 & 5,0 & 100 \\
Fab. Químicos e F. Sinte. & 5,0 & 30,0 & 50,0 & 15,0 & 100 \\
Fab. Artigos de Borracha & 16,7 & 41,7 & 41,7 & 0,0 & 100 \\
Fab. Produtos Minerais & 4,2 & 47,9 & 45,8 & 2,1 & 100 \\
Ind. Metalúrgica de Base & 6,7 & 51,1 & 35,6 & 6,7 & 100 \\
Fab. de Maq. e Equipam. & 8,5 & 40,4 & 46,8 & 4,3 & 100 \\
Fab. de Equip. Eléctrico & 8,3 & 37,5 & 37,5 & 16,7 & 100 \\
Fab. de Mat. de Transporte & 5,1 & 21,1 & 52,6 & 21,1 & 100 \\
Ind Tran. M. Construção & 15,8 & 52,6 & 31,6 & 0,0 & 100 \\
Comércio Grosso/Retalhi. & 7,1 & 28,6 & 42,9 & 21,4 & 100 \\
Alojamento e Restauração & 25,8 & 41,9 & 32,3 & 0,0 & 100 \\
Transporte Armazenagem & 50,0 & 0,0 & 50,0 & 0,0 & 100 \\
Actividades Financeiras & 11,1 & 0,0 & 66,7 & 22,2 & 100 \\
Serviços e Empresas & 7,7 & 23,1 & 30,8 & 38,5 & 100 \\
Outros & 50,0 & 31,8 & 18,2 & 0,0 & 100 \\
\hline
\end{tabular}

Fonte: IAPMEI - Ministério da Economia, 1993.

Atendendo ao estatuto das entidades observa-se que, em termos globais, existe um claro predomínio das sociedades privadas, especialmente aquelas em que o poder e o controlo se concentram na mesma pessoa.

Considerando conjuntamente a dimensão das empresas e o seu estatuto, apreciam-se várias tendências. Em primeiro lugar vê-se que, enquanto as empresas privadas cujo gerente é o proprietário têm, em mais de metade dos casos, uma dimensão inferior a 100 empregados, ou seja, são pequenas; as empresas, também privadas, mas que distinguem a propriedade do controlo, empregam mais de 100 pessoas por unidade. Isto indica que à medida que aumenta o tamanho de uma empresa, o seu proprietário tende a recorrer à contratação de gerentes profissionais. 
Quadro 3

DISTRIBUIÇÃO DAS PME's SEGUNDO O ESTATUTO, EM 1993, EM PERCENTAGEM

\begin{tabular}{|l|c|c|c|c|c|}
\hline \multicolumn{1}{|c|}{ Estatuto } & $\begin{array}{c}\text { Micro } \\
\text { Empresas }\end{array}$ & $\begin{array}{c}\text { Pequenas } \\
\text { Empresas }\end{array}$ & $\begin{array}{c}\text { Médias } \\
\text { Empresas }\end{array}$ & $\begin{array}{c}\text { Grandes } \\
\text { Empresas }\end{array}$ & Total \\
\hline Capital Misto & 28,6 & 0,0 & 57,1 & 14,3 & 100 \\
Subsidiária & 2,3 & 20,5 & 52,3 & 25,0 & 100 \\
Joint Venture & 0,0 & 33,3 & 66,7 & 0,0 & 100 \\
Privada, prop. Do Gerente & 15,3 & 43,4 & 38,4 & 2,9 & 100 \\
Privada, Gerente n/ Prop. & 13,0 & 14,5 & 59,4 & 13,0 & 100 \\
Pública & 0,0 & 0,0 & 80,0 & 20,0 & 100 \\
Inst. Humanitária & 0,0 & 50,0 & 50,0 & 0,0 & 100 \\
Outra & 8,3 & 12,5 & 58,3 & 20,8 & 100 \\
\hline
\end{tabular}

Fonte: IAPMEI - Ministério da Economia, 1993.

Ao analisarmos a evolução empresarial portuguesa nos anos de 1989 a 1993, verificamos que o estatuto de PME atribuído à empresa portuguesa não é recente. O número de empresas, que se enquadra nos escalões de menor dimensão, vem reforçando progressivamente a sua posição. Com efeito, as empresas que empregam entre 0 a 4 trabalhadores são as únicas que, em termos percentuais, aumentaram a sua representatividade na malha empresarial portuguesa, de 1989 para 1993, verificando-se um acréscimo de três pontos.

Estudos realizados, pelo gabinete de apoio à criação de empresas do IAPMEI, revelam que, durante o período de 1983 a 1993, 150000 novas sociedades surgiram em Portugal. Este número, sendo considerável face à nossa estrutura empresarial, corresponde, no entanto, apenas a parte do total de empresas criadas - aquelas que adoptaram a forma jurídica de sociedade, não considerando, portanto, as empresas em nome individual. Relativamente a estas últimas os registos existentes não são seguros mas, face ao peso que detêm ainda no tecido empresarial português, tudo leva a querer que o número de novas empresas em nome individual tenha sido igualmente considerável. 


\section{Quadro 4 \\ EVOLUÇÃO DAS PME's POR ESCALÃO DIMENSIONAL, 1989/93 (EM PERCENTAGEM)}

\begin{tabular}{|c|c|c|c|c|c|c|c|}
\hline \multicolumn{7}{|c|}{ Escalão dimensional-número de trabalhadores } \\
\hline Anos & $0-4$ & $5-9$ & $10-49$ & $50-99$ & $100-199$ & $200-499$ & $>-500$ \\
\hline 1989 & 52,6 & 22,2 & 19,9 & 2,4 & 1,1 & 0,6 & 0,3 \\
1990 & 52,6 & 23,0 & 19,9 & 2,6 & 1,1 & 0,6 & 0,3 \\
1991 & 53,0 & 22,9 & 19,7 & 2,6 & 1,1 & 0,6 & 0,3 \\
1992 & 54,3 & 22,5 & 19,1 & 2,4 & 1,0 & 0,6 & 0,2 \\
1993 & 55,6 & 22,3 & 18,3 & 2,2 & 1,0 & 0,4 & 0,17 \\
\hline
\end{tabular}

Fonte: Departamento de Estatística do MESS - Quadros de Pessoal 1989 a 1993, in IEFP, 1995.

Pela análise dos dados sobre a distribuição do volume anual de vendas pelos vários escalões dimensionais de empresas, em 1993, podemos verificar que as PME's assumem também, neste contexto, um papel determinante. Com efeito, mais de $78,5 \%$ do volume global de vendas no ano de 1993 pode ser imputado a empresas com menos de 500 trabalhadores.

Uma análise mais apurada revela um outro aspecto interessante, que se prende com o contributo, neste contexto, das empresas de menor dimensão. Assim, verifica-se que as empresas que empregam até 50 trabalhadores contribuem com mais de $50 \%$ do total das vendas, cabendo cerca de $11 \%$ às empresas com menos de 5 trabalhadores, cerca de $8 \%$ às empresas entre 5 e 9 trabalhadores e mais de $34 \%$ às empresas entre 10 e 49 trabalhadores.

\section{Quadro 5 \\ VENDAS SEGUNDO O ESCALÃO DIMENSIONALDAS EMPRESAS EM 1993 (EM $10^{3}$ PTE)}

\begin{tabular}{|c|c|c|c|c|c|c|c|c|}
\hline \multicolumn{8}{|c|}{ Escalão dimensional-número de trabalhadores } \\
\hline \multirow{3}{*}{ Valor } & $0-4$ & $5-9$ & $10-49$ & $50-99$ & $100-199$ & $200-499$ & $>=500$ & Total \\
\cline { 2 - 9 } & 3.271 .085 & 2.316 .412 & 10.233 .645 & 2.605 .738 & 2.395 .249 & 2.676 .699 & 6.379 .244 & 29.878 .071 \\
\hline$\%$ & 11,0 & 7,7 & 34,3 & 8,7 & 8,0 & 9,0 & 21,4 & 100 \\
\hline
\end{tabular}

Fonte: Departamento de Estatística do MESS - Quadros de Pessoal, 1993 in IEFP, 1995.

Mas, e apesar de todas estas contribuições e constatações, certo é que a turbulência do meio envolvente torna cada dia mais difícil a sobrevivência e o êxito destas empresas. $O$ avanço tecnológico, a exigência dos consumidores face a novos produtos, as diferentes regulamentações, o aumento da competitividade internacional, a falta de formação adequada do empresário e seus colaboradores, a velocidade da informação, o difícil acesso 
aos sistemas de financiamento, são alguns dos factores que dificultam o desenvolvimento das PME's (Leader Magazine, 1993-1994, nº 5).

As PME's Portuguesas constituem em 1993 com 79,8\% do emprego total. Em contrapartida, as GE empregam $20,2 \%$ dos efectivos nacionais, no mesmo período.

\section{Quadro 6}

EMPREGO NAS PME's , GE E TOTAL EM 1993

\begin{tabular}{|c|c|c|c|c|c|}
\hline \multicolumn{2}{|c|}{ PME's } & \multicolumn{2}{c|}{ GE } & \multicolumn{2}{c|}{ TOTAL } \\
\hline Emprego & $\%$ & Emprego & $\%$ & Emprego & $\%$ \\
\hline 1.769 .861 & 79,8 & 446.623 & 20,2 & 2.216 .484 & 100 \\
\hline
\end{tabular}

Fonte: Departamento de Estatística do MESS - Quadros de Pessoal 1993 in IEFP, 1995.

À semelhança da analise feita ao número de empresas verifique-se, agora, a evolução registada nos últimos anos na distribuição do emprego por dimensão das empresas. Durante o período de 1989 a 1993 assistiu-se a um reforço do peso do emprego nas empresas de dimensão até 200 trabalhadores, em detrimento das empresas de dimensão superior.

Este reforço foi, sem sombra de dúvida, mais evidente nas empresas de menor dimensão, ou seja, nas empresas com menos de 50 trabalhadores que, no seu conjunto, corresponderam a um aumento de representatividade da ordem dos $5,2 \%$.

Há, no entanto, um aspecto que deve ser salientado relativamente ao papel desempenhado pelas empresas de muito pequena dimensão, em termos de emprego local; o emprego por conta própria em pequenas estruturas, especialmente de prestação de serviços e comércio, pode adquirir um significado importante em termos de ocupação de postos de trabalho, embora estatisticamente não seja relevante.

Quadro 7

EVOLUÇÃO DO EMPREGO POR ESCALÃO DIMENSIONAL, 1989/93 EM PERCENTAGEM

\begin{tabular}{|c|c|c|c|c|c|c|c|c|}
\hline \multicolumn{10}{|c|}{ Escalão dimensional-número de trabalhadores } \\
\hline Anos & $0-4$ & $5-9$ & $10-49$ & $50-99$ & $100-199$ & $200-499$ & $>-500$ & Total \\
\hline 1989 & 7,9 & 9,4 & 25,0 & 10,9 & 9,8 & 12,0 & 25,0 & 100 \\
1990 & 8,1 & 9,5 & 25,3 & 11,2 & 10,0 & 11,9 & 24,0 & 100 \\
1991 & 8,4 & 9,7 & 25,7 & 11,6 & 9,9 & 11,8 & 23,0 & 100 \\
1992 & 9,0 & 10,2 & 26,6 & 11,4 & 10,0 & 11,8 & 21,1 & 100 \\
1993 & 9,7 & 10,8 & 27,0 & 11,4 & 10,0 & 11,0 & 20,2 & 100 \\
\hline
\end{tabular}

Fonte: Departamento de Estatística do MESS - Quadros de Pessoal 1989 a 1993, in IEFP, 1995. 
Apesar de toda esta fragilidade na quantidade e qualidade do emprego oferecido pelas PME's, a atenção hoje dada ao modelo da especialização flexível do desenvolvimento das PME's, baseado em índices mais elevados de qualidade, processamento e inovação, sugere que há uma alternativa, através destas mesmas PME's, ao desenvolvimento desintegrado que se tem efectuado nos últimos anos. Para este facto têm contribuído os programas nacionais e comunitários de apoio, não só à PME enquanto estrutura física, mas e sobretudo à formação profissional e às ajudas à contratação.

São alguns os autores que sugerem que as PME's têm certas vantagens sobre as grandes companhias no capítulo da inovação. Os proprietários /gestores dotados de espírito empreendedor podem reagir rapidamente a novas oportunidades tecnológicas e de mercado, e mostram-se, por norma, mais dispostos a aceitar projectos inovadores de alto risco, do que os gestores das GE. Por outro lado, as PME's adoptam frequentemente estratégias eficientes para a resolução dos problemas internos, o que lhes facilita a adaptação a quaisquer alterações surgidas no ambiente externo. As PME's também têm, contudo, algumas desvantagens inerentes em matéria de inovação, nomeadamente: falta de recursos financeiros; mão-de-obra inadequada; incapacidade de alcançar economias de escala na produção e no marketing e restrições na identificação e utilização de fontes externas de informação científica e técnica.

Harrison e Hart (1983) descobriram que, para a globalidade da população das PME's, existe um elo muito significativo entre produto, processo de inovação e desempenho empresarial, quer em termos de resultados líquidos, quer de desenvolvimento do mercado, podendo assim as PME's inovadoras exercer um efeito significativo no desenvolvimento económico dos meios rurais.

Mas, quando se fala em inovação por parte de qualquer empresa 0 primeiro indicador considerado, na maior parte da bibliografia consultada, são as despesas que estas realizam em Investigação e Desenvolvimento (I\&D). Tais despesas relacionam-se com o volume de vendas (trata-se de conhecer a proporção que representa $\circ$ gasto em I\&D sobre $\circ$ volume de vendas) para poder determinar a sua intensidade em I\&D.

Neste sentido, o IAPMEI realizou em 1995 um estudo denominado "Dimensão e Inovação Empresarial", onde os dados mostram claramente uma redução da intensidade em I\&D à medida que aumenta a dimensão das empresas. Assim, enquanto que as micro-empresas, em média, dedicam a I\&D $8,43 \%$ do seu volume de vendas, as pequenas dedicam $2,81 \%$, as médias $2,09 \%$ e as grandes $1,36 \%$ (IAPMEI, 1995, $\mathrm{n}^{\circ} 18$ ).

Quanto à evolução futura do esforço em I\&D, os dados são ainda mais impressionantes, pois embora, em princípio, todas as empresas declarem uma 
intenção de aumentar os seus gastos em I\&D, esse aumento será menor à medida que a dimensão da empresa cresce. A principal conclusão que se pode extrair destes resultados é que a intensidade em I\&D das GE será cada vez menor em termos relativos, pois são as que realizam o menor esforço em I\&D e as que prevêem aumentá-lo menos. A situação oposta dá-se nas pequenas empresas, pois estas realizam um esforço muito maior e, além disso, são as que vão aumentá-lo mais. As micro-empresas, que ostentam o nível máximo de intensidade em I\&D, não vão aumentar o seu esforço tanto como as pequenas, por problemas de saturação (IAPMEI, 1995, $\mathrm{n}^{\circ} 18$ ).

Uma vez mais estamos perante o quadro da União Europeia, já pensado e visto nestes termos em 1983 por Harrison e Hart, segundo o qual PME's inovadoras poderão exercer um papel importante no desenvolvimento local. Mas o que serão PME's inovadoras ao nível local? Como contribuirá essa inovação, das PME's ao nível local, para a melhoria da qualidade de vida das populações locais? Quanto a nós, todas estas dúvidas seriam esclarecidas com uma resposta breve: as PME's criadas localmente atingirão os objectivos a que se propuseram, uma vez satisfeitas as necessidades das populações locais, contribuindo assim para a melhoria da sua qualidade de vida.

As análises e reflexões anteriores espelham, sem dúvida, o significado que, ao longo dos últimos anos, a criação de novas empresas tem vindo a adquirir. No entanto, as "performances" atingidas podem ainda ser melhoradas, uma vez que o desaparecimento prematuro de novas empresas mantém-se muito elevado, não só na Europa como a nível nacional. Há, efectivamente, que procurar modificar esta situação, uma vez que a criação de empresas apresenta um duplo impacto com reflexos nítidos na vertente empresarial e na componente emprego.

A criação de empresas actua, quer através da inclusão de novos dinamismos (novos empresários motivados para o sucesso e com maior capacidade de adaptação às novas realidades tecnológicas e de mercado), quer através da criação de novas actividades ou, ainda, pela via do estímulo a novos modelos de relação intra-empresarial. Por outro lado, a criação de empresas revela-se da maior importância na óptica do emprego, designadamente na sua reorganização, reinserção e criação de postos de trabalho. Com efeito, se pelo facto de associarmos ao conceito de criação de empresas o de empresas de pequena dimensão, poderíamos ser levados a concluir por um menor impacto em termos de emprego, face ao seu contributo moderado para o recrutamento de pessoal, tal já não será verdadeiro em termos de dinâmica de criação do próprio emprego. Esta é uma das razões que justificam o interesse crescente pela problemática da 
criação de empresas, em particular pelo aumento da taxa de sucesso das empresas nascentes.

Reconhecendo a fragilidade do elevado número de empresas nascentes, deficientemente dotadas dos meios indispensáveis à sua sobrevivência, designadamente de meios humanos, cada vez mais os países apostados no desenvolvimento das suas estruturas económicas procuram estratégias tácticas e instrumentos que propiciem a criação de condições de perenidade das novas empresas.

Também na optica da consolidação e do desenvolvimento das empresas existentes, o problema dos recursos humanos, enquanto factor determinante da competitividade, parece ser da maior importância, apontando para a adopção de esquemas de formação adaptados às características de flexibilidade e facilidade de reconversão; trata-se de aspectos peculiares das PME's, que conferem uma importância estratégica a este segmento, quer em termos de equilíbrio da estrutura empresarial, quer em termos de factor dinâmico no processo de desenvolvimento. Neste contexto, as PME's existentes ou a criar tirarão um partido substancialmente maior, caso se verifique um ajustamento entre a formação efectuada e as necessidades das empresas.

Num cenário de mudança, haverá que optar por estratégias que permitam à PME nascente ou já em actividade manter as suas virtualidades, estimulando a abertura a novas práticas de gestão, de tal modo que a sua adopção conduza a um acentuado aumento de competitividade. Por tal motivo, uma atenção especial deve ser dada aos factores não preço, ou factores dinâmicos de competitividade, entre os quais se incluem a inovação e as novas tecnologias. Com efeito, a inovação e as novas tecnologias, não só ao nível do produto como ao nível da gestão, podem conferir às PME's locais capacidades que lhes permitam competir, em determinados nichos de mercado, com as suas congéneres europeias e mesmo com empresas de maior dimensão. Perante um mercado doméstico de pequena dimensão, a conquista de mercados externos deverá ter como vector estratégico a diferenciação dos produtos pela via da qualidade e da criação de marcas próprias. No entanto, quer se trate de empresas nascentes quer de empresas já existentes, os resultados esperados pela introdução da inovação e de novas tecnologias só serão visíveis se as empresas dispuserem de adequados níveis de investimento e massa crítica, designadamente no que concerne aos seus promotores. 


\section{RESULTADOS DE ÂMBITO GERAL DO INVESTIMENTO EM PME's NAS 20 ZI(s) LEADER I EM PORTUGAL: RESPOSTAS A ALGUMAS QUESTÕES}

\subsection{Quantos foram os projectos de investimento em PME's?}

De acordo com a classificação da Comissão Nacional de Gestão, foram recenseados 1097 projectos de apoio a PME's, o que corresponde a 50\% do total de projectos.

\subsection{Qual a forma jurídica dos promotores do investimento em PME's?}

Através das três classificações "préestabelecidas" para a forma jurídica dos promotores, podemos verificar, pelo estudo efectuado, que são os promotores privados aqueles que apresentam um maior número de projectos (76,5\%) de investimento em PME's nas ZI(s) em estudo. Os promotores públicos representaram, neste processo, $17,8 \%$ do total de projectos e os outros apenas $5,7 \%$. Desta análise, somos levados a concluir que, embora os privados tenham tido forte presença neste tipo de investimento, os públicos ainda são chamados a participar nele, sobrepondo-se à classificação outros, onde inserimos todas as organizações sem fins lucrativos.

\subsection{Qual o sector de actividade a que pertencem as PME's criadas ou apoiadas?}

Dos três sectores de actividade existentes apenas dois são preferidos neste tipo de investimento: os serviços, com 908 projectos de investimento $(82,8 \%$ do total dos projectos PME's), e a produção, com 189 (17,2\%) projectos de investimento.

\subsection{Quais as medidas onde se verificam maior número de projectos de investimento em PME's?}

Das seis medidas que compreendem a estratégia de actuação do Leader I, verifica-se, através da tabela anterior, que a mais penalizada, em termos de investimento em PME's, foi a medida 6 (Outras Medidas), com 32 projectos 
a nível nacional. Contrariamente, a medida mais procurada para este tipo de investimento foi a medida 3 (Turismo em Espaço Rural), com 478 projectos, representando este valor $43,6 \%$ do total dos projectos de investimento em PME's.

2.5. Para que sector de actividade (secundário ou terciário) direccionaram estes promotores (privados, públicos e outros) o seu investimento?

O número total de empresas, resultantes do cruzamento das duas variáveis, é de 1097. O valor esperado é calculado, admitindo que existe uma relação de independência entre as duas variáveis. Dos 908 promotores que investem nos serviços, verificamos que $73,7 \%$ (669 promotores) são promotores privados. Neste sector, encontram-se 79,7\% (669 promotores) do total dos promotores privados (839). Do número total de empresas (1097), $61 \%$ (669) são promotores privados e investiram nos serviços.

Quando analisamos os dados sob o prisma de tentar saber para que sector de actividade (secundário ou terciário) direccionaram estes promotores o seu investimento, a resposta é a seguinte:

- $82,8 \%$ dos promotores fizeram o seu investimento em PME's de serviços e 17,2\% em PME's de produção;

- do total do investimento em PME's de serviços, 73,7\% foram promotores privados, $20,9 \%$ públicos e $5,4 \%$ com outra forma jurídica.

- do total do investimento em PME's de produção, $89,9 \%$ foram promotores privados, $2,6 \%$ públicos e $7,4 \%$ com outra forma jurídica. De notar aqui a inversão na preferência dos promotores das instituições sem fins lucrativos sobre os promotores públicos. É provável que, para este facto, tenham contribuído as Associações de produtores de artesanato.

\subsection{Como se repartem as PME's apoiadas pelas 6 medidas (ou eixos de actuação) face à forma jurídica do promotor do investimento?}

Do total dos projectos de investimento em PME's, é notória a preferência dos promotores privados (327 projectos) e públicos (137 projectos) pela medida 3 (Turismo em Espaço Rural) dos 478 concretizados nesta medida. 
De outra forma, podemos dizer que os promotores privados fazem a hierarquização dos seus investimentos, por medida, da seguinte forma:

- $39 \%$ para a medida 3;

- $37,5 \%$ para a medida 4 ;

- $14,5 \%$ para a medida 5 ;

- $4,6 \%$ para a medida 2 ;

- $2,4 \%$ para a medida 1 e $1,9 \%$ para a medida 6 .

Os promotores públicos ordenam as suas preferências da seguinte forma:

- $70,3 \%$ para a medida 3;

- $11,3 \%$ para a medida 5 ;

- $6,7 \%$ para a medida 6 ;

- $5,6 \%$ para a medida 4

- $4,1 \%$ para a medida 1 e $2,1 \%$ para a medida 2 .

Quanto aos outros promotores, as preferências são as seguintes:

- $23,8 \%$ para a medida 4 ;

- $22,2 \%$ para a medida 3 ;

- $20,6 \%$ para a medida 5 ;

- $17,5 \%$ para a medida 1 ;

- $11,1 \%$ para a medida 2 e $4,8 \%$ para a medida 6 .

É de notar que este último grupo de promotores apresenta uma distribuição nas suas preferências mais homogénea. Outra característica apresentada pelo grupo é a forte tendência para as medidas 1 e 2 , minimizadas pelos grupos anteriores.

\subsection{Como se repartem as PME's apoiadas ou criadas pelas 6 medidas (ou eixos de actuação), face ao sector de actividade a que pertencem?}

As medidas (ou eixos de actuação) que maior número de projectos apoiam nos serviços são as medidas 3 (Turismo em Espaço Rural) e 6 (Outras Medidas), ambas com $100 \%$ dos seus projectos de investimento em PME's. Na produção, as medidas que se destacam são: a medida 4 (PME's, Artesanato e serviços de Apoio), com $37,2 \%$ dos seus projectos de investimento em PME's e a medida 5 (Valorização e Comercialização de Produtos Locais), com $33,1 \%$ do total dos seus projectos de investimento em PME's. 


\subsection{Quantos foram os projectos de investimento em PME's no interior e no litoral?}

Pela tabela de resultados apurada, podemos verificar que, dos 1097 projectos de investimento em PME's, $699(63,7 \%)$ foram concretizados em regiões do interior e apenas 398 (36,3\% em regiões do litoral).

\subsection{Qual a forma jurídica dos promotores dos projectos de investimento em PME's no interior e no litoral?}

Verifica-se que os promotores dos projectos de investimento em PME's são, na sua maioria, privados $(76,5 \%)$ e de zonas do interior $(63,7 \%)$. Também os promotores públicos registam maior dinamismo, no investimento PME's, no interior $(71,8 \%)$ do que no litoral $(28,2 \%)$. Contrariamente, os outros promotores (onde se encontram as instituições sem fins lucrativos) mostram maior dinamismo no litoral $(63,5 \%)$ do que no interior $(36,5 \%)$.

2.10. Para que sector de actividade (serviços ou produção) direccionaram os agentes locais, do interior e do litoral, os seus projectos de investimento em PME's?

Analisando os resultados obtidos, por forma a responder à questão formulada, verificamos que os promotores do interior direccionam os seus investimentos para os serviços $(81,5 \%)$, afectando apenas à produção $18,5 \%$ dos seus projectos de investimento em PME's. Os promotores do litoral mantêm esta preferência, afectando $84,9 \%$ aos serviços e $51,1 \%$ à produção.

\subsection{Quais as medidas (ou eixos de actuação) que maior número de projectos de investimento em PME's acolhem no interior e no litoral?}

Como já tivemos oportunidade de referir, no que diz respeito à medida 3 , é o interior que maior número de projectos de investimento em PME's detém. No entanto, é de realçar, através do cruzamento destas duas variáveis e em relação a cada uma das referidas zonas, o seguinte: no interior, os projectos de investimento em PME's são repartidos pelas 6 medidas da seguinte forma: 
- medida 1 - 3,1\% do total de projectos de investimento em PME's;

- medida 2 - 5,6\% do total de projectos de investimento em PME's;

- medida $3-42,1 \%$ do total de projectos de investimento em PME's;

- medida $4-28,6 \%$ do total de projectos de investimento em PME's;

- medida 5 - $17,5 \%$ do total de projectos de investimento em PME's;

- medida 6 - 3,1\% do total de projectos de investimento em PME's.

No litoral, a repartição dos projectos de investimento em PME's pelas 6 medidas é a seguinte:

- medida 1 - 4,3\% do total de projectos de investimento em PME's;

- medida 2 - 2,8\% do total de projectos de investimento em PME's;

- medida 3 - 46,2\% do total de projectos de investimento em PME's;

- medida $4-35,4 \%$ do total de projectos de investimento em PME's;

- medida $5-8,8 \%$ do total de projectos de investimento em PME's;

- medida 6 - 2,5\% do total de projectos de investimento em PME's.

Dito de outra forma, o interior apresenta maior percentagem de projectos, face ao litoral, nas medidas 2,5 e 6 .

\subsection{Quantos foram os postos de trabalho criados nas PME's apoiadas?}

Foram 947 os postos de trabalho criados através do investimento realizado em PME's. É de notar que 56,8\% das empresas criam apenas um único novo posto de trabalho. 


\subsection{Quais as PME's que maior número de postos de trabalho criaram, as do interior ou as do litoral?}

Pelos valores obtidos, verificamos que são as PME's do interior que criam maior número de postos de trabalho (626), 66,1\% do total de novos postos de trabalho criados (947).

\subsection{Como se repartem os postos de trabalho criados pelas PME's em análise no interior e no litoral face, à forma jurídica dos promotores dos projectos?}

São as PME's do interior, com promotores privados, aquelas que maior número de postos de trabalho criam, com 463 novos postos de trabalho dos 946 criados a nível nacional. No entanto, enquanto os promotores privados e públicos apresentam maior dinamismo na criação de emprego no interior, os outros promotores apresentam melhores resultados, na criação de novos postos de trabalho, no litoral com $63,5 \%$ do total de emprego criado por este grupo de promotores.

\subsection{Tendo em atenção a localização geográfica das PME's apoiadas, qual o sector de actividade mais dinâmico na criação de emprego?}

Do total dos postos de trabalho criados nas PME's em estudo, 82,9\% foram nos serviços e $17,1 \%$ na produção. Podemos, ainda, verificar que $54,4 \%$ dos postos de trabalho criados foram nos serviços e no interior, $28,4 \%$ nos serviços e no litoral, $11,6 \%$ na produção e no interior e $5,5 \%$ na produção, no litoral. É o sector produtivo do litoral que menor número de postos de trabalho cria (apenas 52 novos postos de trabalho).

2.16. Quais as medidas (ou eixos de actuação) onde se situam as PME's mais dinâmicas na criação de novos postos de trabalho? Qual a sua localização geográfica?

Como já tivemos oportunidade de referir, foi no interior que se registou a criação de maior número de novos postos de trabalho. No entanto, ao cruzarmos as variáveis localização geográfica com a medida (ou eixo de 
actuação), verificamos que esta superioridade é válida em qualquer medida. Isto é, quando analisamos a criação de novos postos de trabalho nas respectivas medidas, é no interior que encontramos as maiores percentagens. Dentro das 6 medidas, é a medida 3 aquela que gera maior número de postos de trabalho, repartidos em $78 \%$ para o interior e $22 \%$ para o litoral. A esta medida, segue-se a medida 4 (20,3\% no total), com $66,7 \%$ no interior e $33,3 \%$ no litoral. A medida que maior número de postos de trabalho cria no litoral é a medida 1 , com $33,3 \%$ dos 192 novos postos de trabalho criados nesta medida.

\section{REFLEXÕES FINAIS}

Embora dos objectivos do presente trabalho conste a análise da inovação, revelou-se difícil a obtenção de elementos quantitativos que nos levem à apreciação da capacidade inovadora das PME's Leader, nomeadamente no que diz respeito aos investimentos em Marketing, I\&D e Formação. No entanto, outras vertentes inovadoras podem ser analisadas. Se pensarmos que inovar se consubstancia em produzir algo de novo, encontrar um novo processo produtivo ou de comercialização ou, mesmo, renovar um já existente, facilmente admitimos que o carácter inovador destes investimentos (PME) pode ser enquadrado em, pelo menos, quatro níveis: quadro institucional local; localização geográfica dos investimentos; estado de espírito dos agentes locais; e criação de novos postos de trabalho.

Quanto ao primeiro nível, quadro institucional local, podemos começar por referir a criação de novas instituições de desenvolvimento local em meios rurais (onde mais de $38 \%$ da população activa está ligada ao sector agrícola), resultantes da implementação do programa Leader I em Portugal. $O$ resultado foi proporcionar a coordenação e a convergência de esforços dos vários agentes locais no sentido do desenvolvimento dos seus próprios territórios. O consequente aparecimento de 1097 PME's criadas e /ou reforçadas nas suas diversas estruturas e a predominância dos investimentos privados, sobre os públicos ou outros, leva-nos a encarar a possibilidade de se ter desencadeado um processo de correcção de defeitos estruturais, principalmente no interior do país.

Do ponto de vista da localização geográfica, facilmente admitimos que algo de completamente novo se passou. Senão vejamos: a maior parte do investimento Leader I, quer na análise efectuada globalmente, quer na sua vertente PME's, foi efectuado em zonas com baixa densidade populacional do interior do país, onde a população ligada ao sector agrícola é ainda, em 
média, $45 \%$, e onde $61 \%$ da população activa tem menos de 25 anos ou mais de 64 anos. Este facto permite-nos afirmar que estamos perante uma estratégia inovadora no sentido de cobrir nichos geográficos desfalcados de qualquer tipo de investimento fora do sector agrícola. Apesar de não sabermos ao certo qual a sustentabilidade destes investimentos, cremos ser possível concluir que foram, provavelmente, tapados mais uns quantos buracos ao serem levados a cabo investimentos em PME's, tanto por promotores privados, como públicos ou outros, por forma a assegurar o arranque de um processo de desenvolvimento económico, nestes territórios.

O terceiro nível, a que chamámos de estado de espírito dos agentes locais, parece-nos ser aquele onde realmente a inovação neste tipo de investimento mais se fez sentir. O carácter inovador pode ser visto, tanto pela tentativa de desenvolvimento da parceria dos agentes do desenvolvimento endógeno, actores do desenvolvimento local, em sentido ascendente, como na inovação e no intercâmbio de experiências. Outra das dimensões deste estado de espírito e, quanto a nós, uma das mais importantes, foi a vontade assumida e desencadeada pelas próprias populações locais no sentido de investir na melhoria das suas condições de vida pela satisfação das suas próprias necessidades.

Por último, a criação de novos postos de trabalho por parte das PME's apoiadas, pese embora o facto de se integrarem predominantemente na área dos serviços, contribuíram, ainda que de forma pouco expressiva, para a fixação das populações em territórios essencialmente rurais, minimizando a permanente descapitalização das zonas rurais de todos os seus recursos humanos e sociais.

Chegados a este ponto, e não obstante os resultados obtidos, damo-nos conta de uma certa insatisfação que se prende com outros aspectos que gostaríamos de ter podido verificar.

A primeira grande limitação tem a ver com o método de recolha de dados utilizado. $\mathrm{O}$ facto dos mesmos terem sido recolhidos junto do órgão gestor do Programa, na ausência de outra fonte de informação em termos nacionais, não permitiu a evidência de outros elementos, tais como:

- a caracterização pormenorizada dos promotores dos projectos;

- a análise dos diversos resultados económicos, já obtidos pelas PME's apoiadas, por forma a avaliar a sustentabilidade destes investimentos;

- a origem dos diversos recursos utilizados pelas PME's em estudo e o destino dos seus produtos finais;

- o número de novos postos de trabalho criados indirectamente e a qualidade dos mesmos; e, 
- as sinergias geradas, directa ou indirectamente, por estes investimentos.

Perante estas e outras interrogações, que nos possam ter escapado, poder-se-á colocar a seguinte questão: será que, com todo este investimento, o sistema local gerou capacidades de representação colectiva e as utiliza perante o seu exterior para a negociação do seu próprio processo de desenvolvimento? Esperamos, ainda assim, que este estudo seja um pequeno contributo para a clarificação de várias questões e que o mesmo possa contribuir para melhores desempenhos futuros, tanto por parte dos agentes promotores do desenvolvimento local em meio rural, como do próprio acto de investigar. Conscientes de que este trabalho é apenas uma aproximação ao problema e que o mesmo não deve terminar aqui, seria interessante que, num futuro breve, todas as dúvidas e limitações atrás evidenciadas obtivessem uma resposta, no sentido de um maior conhecimento endógeno dos processos de desenvolvimento local dos meios rurais.

Para terminar, evocando Schumpeter, diríamos que, apesar de tudo, o Leader I e os seus investimentos contribuíram, de certa forma, para colocar na fase ascendente do processo de desenvolvimento economias periféricas, como as que tipificam as $\mathrm{ZI}(\mathrm{s})$ dos programas Leader em análise, pois este "começa quando algum empresário quebra o equilíbrio existente com uma nova inovação” (Gill, 1967:155).

\section{NOTAS}

-Apresentado no $6^{\circ}$ Congreso de Economía Regional de Castilha y León, Zamora, 26-28 de Novembro de 1998.

IObjectivo I: "Promover o desenvolvimento e o ajustamento estrutural das regiōes menos desenvolvidas". Estas foram caracterizadas como sendo áreas que não acompanharam o progresso de outras Regiões, sendo o seu PIB por habitante inferior a $75 \%$ da média comunitária. Aqui a tónica da intervenção comunitária é colocada na recuperação do atraso através da criação de infra-estruturas sólidas.

Objectivo 5b: "Promover o desenvolvimento das zonas rurais", em áreas representativas das menores densidades populacionais da comunidade sendo, para tal, necessário incentivar o seu desenvolvimento económico. $O$ esforço comunitário incide, no âmbito deste objectivo, na criação de novos postos de trabalho, alheios à actividade agrícola, nomeadamente no campo do turismo e das pequenas empresas e na melhoria dos serviços básicos de forma a evitar o êxodo rural.

2 Adoptando a classificação do Observatório Europeu das PME's foram estabelecidas as seguintes categorias: micro-empresas (de 0 a 9 trabalhadores), pequenas empresas (de 10 a 99 trabalhadores), médias empresas (de 100 a 499 trabalhadores) e grandes empresas (com 500 ou mais trabalhadores). 


\section{REFERÊNCIAS BIBLIOGRÁFICAS}

AMARO, R. R. (1991), "Lógicas de Espacialização da Economia Portuguesa", in Sociologia Problemas e Prática, $\mathrm{n}^{\circ}$ 10, pp. 161-183.

AMARO, R. R. (1993), “As Novas Oportunidades do Desenvolvimento Local”, in A Rede para o Desenvolvimento Local, $\mathrm{n}^{\circ} 8$, pp. 15-22.

BANNOCK, G. (1987), The Economics of Small Firms: Return from the wilderness, Basil Blackwell, Oxford.

BARRETO, A.; PRETO, C. V. (1996), 'Portugal 1960/1995: indicadores sociais", in Cadernos do Público, Lisboa.

BENKO, G.; LIPIETZ, A. (1994), As Regiões Ganhadoras - Distritos e Redes, os novos paradigmas da geografia, Celta Editora Lda, Oeiras.

BUREAU INTERNATIONASL DU TRAVAIL - BIT (1961), Au Service de la Petite Industrie, Genéve.

CARRINHO, M. (1996), O Leader em Portugal - Balanço e Perspectivas, Palavra Oportuna, n², ANIMAR.

CCE (1988), "O Futuro do Mundo Rural: Comunicação da Comissão", Comissão das Comunidades Europeias, Bruxelas.

Comunicação aos Estados-Membros (1991), Jornal Oficial das Comunidades Europeias, $\mathrm{n}^{\circ} \mathrm{C} 73$, Bruxelas.

CRISTÓVÃO, A.; Tibério, M. L. (s./d.), "Elementos para uma Estratégia de Desenvolvimento Endógeno", UTAD, Vila Real.

DINIZ, F. J. L. S. (1995), Desenvolvimento Rural, que Perspectivas? O Caso das Nuts Alto Trás-os-Montes e Douro, Dissertação de Doutoramento, UTAD, Vila Real.

DGPA, Programa de Iniciativa Comunitária LEADER (1993), "Instruçōes e Orientaçōes Práticas para a sua Gestão", Ministério da Agricultura, Lisboa.

Dirigir, Revista Para Chefias (1983), $\mathrm{n}^{\circ}$ especial, Lisboa.

Dirigir, Revista Para Chefias (1992), n²6, Lisboa.

Dirigir, Revista Para Chefias (1995), $\mathrm{n}^{\circ} 35$, Lisboa.

ESMAN, M. J.; UPHOFF, N. T.(1984), Vulnerabilites of Rural Local Organizations, Local Organizations, Intermediaries in Rural Development, Cornelle University, New York.

FIGUEIREDO, A. M.; COSTA, C. S. (1982), Do Subdesenvolvimento-Vulgatas, Ruturas e Reconsiderações em Torno de um Conceito, Vol. I, Edições Afrontamento, Porto. 
GERRY, Chris (1997), " Zonas Rurais na Fronteira da Reestruturação Territorial: Terceira Itália ou Quarto Portugal?", UTAD, Vila Real.

GILL, R. T. (1967), Evolução do Pensamento Económico, Editora LCE, Lisboa.

IAPMEI - Suplemento da Revista Pequena e Média Empresa, nº18, 1995, Lisboa.

IAPMEI - IAPMÉDIA 63; Informação Mensal Para o Empresário, Abril de 1996, Lisboa.

IEFP - Delegação Regional do Norte (1994), "O centro de emprego na imprensa", in textos e recortes, Braga.

IEFP - Delegação Regional do Norte (1995), "O centro de emprego na imprensa", in textos e recortes, Braga.

LATUR, P. (1994), O Apoio às Pequenas e Médias Empresas Rurais, AEIDL, Bruxelas.

Leader Magazine (1992), $\mathrm{n}^{\circ} 1$ e 2, chaussés Saint Pierre 260, B-1040, AEIDL, Bruxelas.

Leader Magazine (1994), n³, chaussés Saint Pierre 260, B-1040, AEIDL, Bruxelas.

Leader Magazine (1993-1994), n5, chaussés Saint Pierre 260, B-1040, AEIDL, Bruxelas, Inverno.

Ministério do Planeamento e Administração do Território, Direcção-Geral do Desenvolvimento Regional (1993), "O Mundo Rural na Estratégia de Desenvolvimento Regional", Lisboa, Janeiro.

Ministério do Planeamento e Administração do Território, Gabinete de Estudos de Planeamento e Administração do Território (1993), "A Evolução Recente e Problemas de Desenvolvimento dos Espaços Rurais", Lisboa, Janeiro.

OCDE, (1990), Rural Development Policy, OCDE, Paris.

OCDE, (1991), Nouvelle Gestion des service dans les Zones Rurales, OCDE, Paris.

Parlamento Europeu, Comissão da Agricultura, Pescas e do Desenvolvimento Rural (1991), Relatório sobre o Programa LEADER e sobre a Utilização das Zonas Rurais, Bruxelas.

PINDER, D. (1994), Europa Ocidental - Desafios e Mudanças, Celta editora Lda, Oeiras. PIORE, Michael e Sabel, Charles (1984), The Second Industrial Divide: Possibilities for Prosperity, Basic Books, New York.

STALEY, E. (1958), "Small Industry Developement", in Research Program on Small Industry Development, Miscelanious, Papers $\mathrm{n}^{\circ} 1$, Starford Research Institute.

STOREY, D. J.; JOHNSON, S. G. (1987), Job creation in Small and Medium Sized Enterprises, Comissão das Comunidades Europeias, Programa de Pesquisa e Acção Sobre o Desenvolvimento de Mercados de Trabalho, vols. 3, Bruxelas.

VAZQUEZ, B. A. (1995), “A Evolução Recente da Política Regional: a Experiência Europeia" in Notas Económicas, Universidade de Coimbra, Coimbra. 